\title{
Road safety practices among school-going children in Chennai
}

\author{
Swathi Padankatti', Uma Narayanan, Jisha Susan Babu, Kuruvilla Thomas \\ From International Summit on Emergency Medicine and Trauma 2014 \\ Puducherry, India. 12-16 February 2014
}

\section{Objective}

To study the awareness and execution of road safety practices among school children.

\section{Methods}

Design: Questionnaire based study

Setting \& Participants: Children studying in 9th \& 10th grades of city schools in Chennai, Tamilnadu, India.

\section{Results}

Questionnaires were completed by 234 (93.6\%) of 250 children who were approached. The mean age of the children was 14.3 (range 13-15 years). 70 (29\%) were girls and 141 (60\%) were boys; 23 (9.8\%) did not fill in the personal details. 12 girls had driven a car or bike, of which 6 always, 4 sometimes and 2 never had driven without a helmet/seat-belt. 66 boys had driven a car or bike of which 32 has always, 22 sometimes and 12 had never driven without a helmet/seat-belt.

$33(47 \%)$ girls and $90(63.8 \%)$ boys had ridden as pillion, of which only 5 boys and no girls wore a helmet. $17(6.8 \%)$ children did not answer this question. 31 (21.9\%) boys and 14 (2\%) girls had had a road traffic accident (RTA); 4 boys and no girls sustained fractures. None of the children had a license. 34 (24\%) boys and $17(24 \%)$ girls used seat-belts in the passenger seat of cars. 10 boys and no girls had used mobile phones when driving. 10 (7\%) boys and 11 (15\%) girls admitted to disregarding traffic signals. $58(41 \%)$ boys and $28(40 \%)$ girls had friends who had an RTA. 22 (15\%) boys and $2(2 \%)$ girls had involved in racing while driving. None had consumed alcohol while driving.
$116(82 \%)$ boys and $49(70 \%)$ girls rode bicycles on the road, $2(4 \%)$ girls and 5 (4.3\%) boys used helmets. 48 mothers and 115 fathers of these children used helmets while driving two wheelers: 60 mothers and 107 fathers used seat-belts while driving cars. 122 (86\%) boys and $59(84.2 \%)$ girls believed that helmets and seat-belts prevent serious injury.

\section{Limitations}

Doing a cluster sampling of all the city schools would have yielded a more holistic picture.

\section{Conclusion}

The non-use of seat-belts, helmets, unlicensed driving of vehicles and scant regard to traffic rules are rampant in school-going children. The law regarding this has to be enforced and punishment maximised to improve road safety practices.

Published: 25 July 2014

doi:10.1186/1865-1380-7-S1-O2

Cite this article as: Padankatti et al:: Road safety practices among school-going children in Chennai. International Journal of Emergency Medicine 2014 7(Suppl 1):O2. 